\title{
Transformation of internal solitary waves at the "deep" and "shallow" shelf: satellite observations and laboratory experiment
}

\author{
O. D. Shishkina ${ }^{1}$, J. K. Sveen ${ }^{2}$, and J. Grue ${ }^{2}$ \\ ${ }^{1}$ Institute of Applied Physics, Russian Academy of Sciences, Nizhny Novgorod, Russia \\ ${ }^{2}$ Mechanics Division, Department of Mathematics, University of Oslo, Oslo, Norway \\ Correspondence to: O. D. Shishkina (olsh@ hydro.appl.sci-nnov.ru)
}

Received: 22 January 2013 - Revised: 15 August 2013 - Accepted: 16 August 2013 - Published: 9 October 2013

\begin{abstract}
An interaction of internal solitary waves with the shelf edge in the time periods related to the presence of a pronounced seasonal pycnocline in the Red Sea and in the Alboran Sea is analysed via satellite photos and SAR images. Laboratory data on transformation of a solitary wave of depression while passing along the transverse bottom step were obtained in a tank with a two-layer stratified fluid. The certain difference between two characteristic types of hydrophysical phenomena was revealed both in the field observations and in experiments. The hydrological conditions for these two processes were named the "deep" and the "shallow" shelf respectively. The first one provides the generation of the secondary periodic short internal waves - "runaway" edge waves - due to change in the polarity of a part of a soliton approaching the shelf normally. Another one causes a periodic shear flow in the upper quasi-homogeneous water layer with the period of incident solitary wave. The strength of the revealed mechanisms depends on the thickness of the water layer between the pycnocline and the shelf bottom as well as on the amplitude of the incident solitary wave.
\end{abstract}

\section{Introduction}

Internal solitary waves generated by nonlinear transformation of internal tide are a common feature of density stratified oceans. Observations of these waves show that they are generated, in particular, in the regions of variable bathymetry such as the shelf edge or bottom irregularities where the tidal flow over the bathymetry forces the pycnocline to oscillate with a tidal frequency.

The phenomenon known as the internal tide is well investigated. There is a wide database of field measurements in different regions of the World Ocean (LeBlond and Mysak,
1978; Lacombe and Richez, 1982; Huthnance, 1989; Morozov, 1995; Miropol'sky, 2001). Reviews on the internal solitary waves generation in both shallow and deep areas of the World Ocean are presented in Ostrovsky and Stepanyants (1989), Grimshaw et al. (2004), Sabinin et al. (2004), Vlasenko et al. (2005), and Helfrich and Mellville (2006). Examples of areas with strong internal tides are the Strait of Gibraltar (Ziegenbein, 1970; Armi and Farmer, 1988; La Violette and Arnone, 1988; Kinder, 1984; Morozov et al., 2002), the Mascarene Ridge (Konyaev et al., 1995; Morozov et al., 2009), Russian Polar Seas (Morozov, 1995; Serebryanyi, 2000), the continental shelf of the UK (Small et al., 1999, 2001, 2003), the Andaman Sea (Osborne and Burch, 1980; Vlasenko and Alpers, 2005), the Alboran Sea (Speich et al., 1996; Lafuente and Delgado, 2004).

Generation and propagation of solitary waves in the shelf zone have been studied theoretically for a long period. Lee and Beardsley (1974) applied the Korteweg-de Vries equation $(\mathrm{KdV})$ for the first time to model the evolution of a shoreward propagating internal tide over the slope and shelf region in the Massachusetts Bay. Then, weakly nonlinear models were used for soliton modeling in the Alboran Sea (Pierini, 1989) and the Strait of Gibraltar (Longo et al., 1992), the shelf of Australia (Holloway et al., 1997, 1999; Grimshaw et al., 1999).

Ostrovsky and Grue (2003) suggested a simple evolution equation as a generalisation of the Korteveg-de Vries and Benjamin-Ono equations, compared the results with the exact numerical calculations and made comparisons with observational data of very strong solitons in the sharp pycnocline. Strongly nonlinear asymptotic models were compared and validated with laboratory experimental observations and results of the numerical integration of Euler equations for solitary internal waves generated at the interface 
of the two-fluid system with shallow and deep fluids by Camassa et al. (2006). Maderich et al. (2010) described the dispersion of an internal solitary wave at a bottom step in a twolayer fluid for three different ratios of the step height to the lower layer thickness after the step. Numerical simulations of the soliton's transformation with the estimation of the energy balance using non-hydrostatic version of the Princeton Ocean Model and a theoretical and numerical study of the Gardner equation were performed.

Packets of high-frequency waves and solitons are distinguished during analysis of remote sensing (SAR) and photography (Baines, 1981; Brandt et al., 1996; Hajji et al., 1998; Rodenas and Garello, 1998; Velegrakis et al., 1999; Klemas et al., 2001; Zheng et al., 2001, 2002; New and Da Silva, 2002; Da Silva et al., 1998, 2007; Zhao et al., 2003; Szekielda et al., 2012; Guo et al., 2012).

Transformation of the finite-amplitude internal solitary waves at a ridge in a two-fluid system has been studied experimentally by Koop and Butler (1981), Segur and Hammack (1982), and Michallet and Ivey (1999). The correlation of the solitary wave's amplitude and its length under deep and shallow water conditions was examined. The effect of the ridge's slope on wave's propagation was studied by Kao et al. (1985), Sveen et al. (2002) and Boegman et al. (2005). Cases of internal wave's blocking and breaking as well as energy loss along the slope, the mixing efficiency versus the breaker type were observed and analysed. Additionally an inversion of the soliton train while its passage under the critical depth of the lower layer of the two-layered fluid has been studied by Cheng et al. (2011).

There is a number of theoretical works (Evans and McIver, 1984; Constantin, 2001; Johnson, 2007, 2008) dealing with generation of surface edge waves by periodic waves of constant frequency. Nonlinear effects in edge waves have been revealed by Whitham (1976) and Yeh (1986). Kurkin and Pelinovsky (2002) studied frequency modulation of the incoming periodic waves resulted in their focusing at the shelf.

Greenspan (1970) found an edge-wave solution in the case of stratified fluid with an exponentially varying density over a sloping beach. Small (2001) studied refraction and shoaling of internal solitary waves due to variations in water depth and nonlinearity with the development of the model to handle realistic ocean stratification and bathymetry (Small, 2003).

A variety of experimental results on edge waves generated at the free water surface could be found in Yeh (1986), Buchan and Pritchard (1995), Liu and Yeh (1996), and Sou and Yeh (2011). There are also first laboratory studies on the internal edge wave formation from regular internal waves over the plain and inclined bottom of the shelf model by Shishkina (2010a, b).

In this paper, mechanisms of transformation of internal solitary waves during their propagation normally to the shelf edge in the stratified fluid with the pronounced near-surface pycnocline are studied. The hydrological conditions were classified as the "deep" shelf when the water layer between the shelf bottom and the pycnocline is comparable with the incident internal wave length, and the case of position of the pycnocline close to the shelf bottom with induced periodic currents in between is named the "shallow" shelf.

The Red Sea and the Alboran Sea were considered as examples of particular regions corresponding to each of the named shelf types. The phenomena observed with satellite photography and remote sensing are described in Sect. 2. The experimental part of the work performed in the laboratory tank filled with a two-layer stratified fluid having a shelf model along the side wall is discussed in Sect. 3.

\section{Field observations}

There is a wide database on satellite observations of propagation of internal solitary waves in different regions of the World Ocean. Here we pay special attention to some particular cases of formation and propagation of a solitary wave (or groups of solitons) in the basins where they could propagate at the angles close to normal to the shoreline.

\section{1 "Deep" shelf}

An example of such internal wave's propagation takes place in the Red Sea. As can be seen in Fig. 1, it is a basin of about $2000 \mathrm{~km}$ long and $300 \mathrm{~km}$ wide, with rugged bottom topography and steep marginal scarps partially isolated from the open ocean. The central bottom depression exceeds $2200 \mathrm{~m}$ in depth and has two crosswise shallow sills, about $125 \mathrm{~m}$ deep in the southern part and the mid-length of the sea. The latter region is known to be almost tideless, the highest tidal level fixed in the North reaches $0.6 \mathrm{~m}$ and in the South $0.9 \mathrm{~m}$ of daily oscillations (Behairy, 1992).

We assume that the water circulation here is affected mainly by the meteorological events (wind, surface pressure, heat flux) in the background of the density gradients in the water column. With the exception of the northern part of the Red Sea, which is dominated by persistent north-west alongshore winds, the rest of the Red Sea is influenced by regular and seasonally reversible winds.

The wind regime is characterised by both seasonal and regional variations in speed and direction with average speed generally increasing northward. In autumn and winter the inflow of less saline water comes from the Gulf of Aden into the Red Sea resulting in an overall drift to the northern end of the Red Sea. This lead to a strong upwelling of more dense bottom waters replacing wind-driven upper water layer near the Eastern sea coast in July-October (see Fig. 2).

According to the bathymetric map of the Red Sea there is a very narrow and steep shelf zone. In some regions the pycnocline approaches the coast very closely. And in the upwelling period has the typical depth of about $50 \mathrm{~m}$, providing a depth of more than $100 \mathrm{~m}$ of the lower water layer along the shelf bottom having $200 \mathrm{~m}$ depth. Such hydrological conditions 


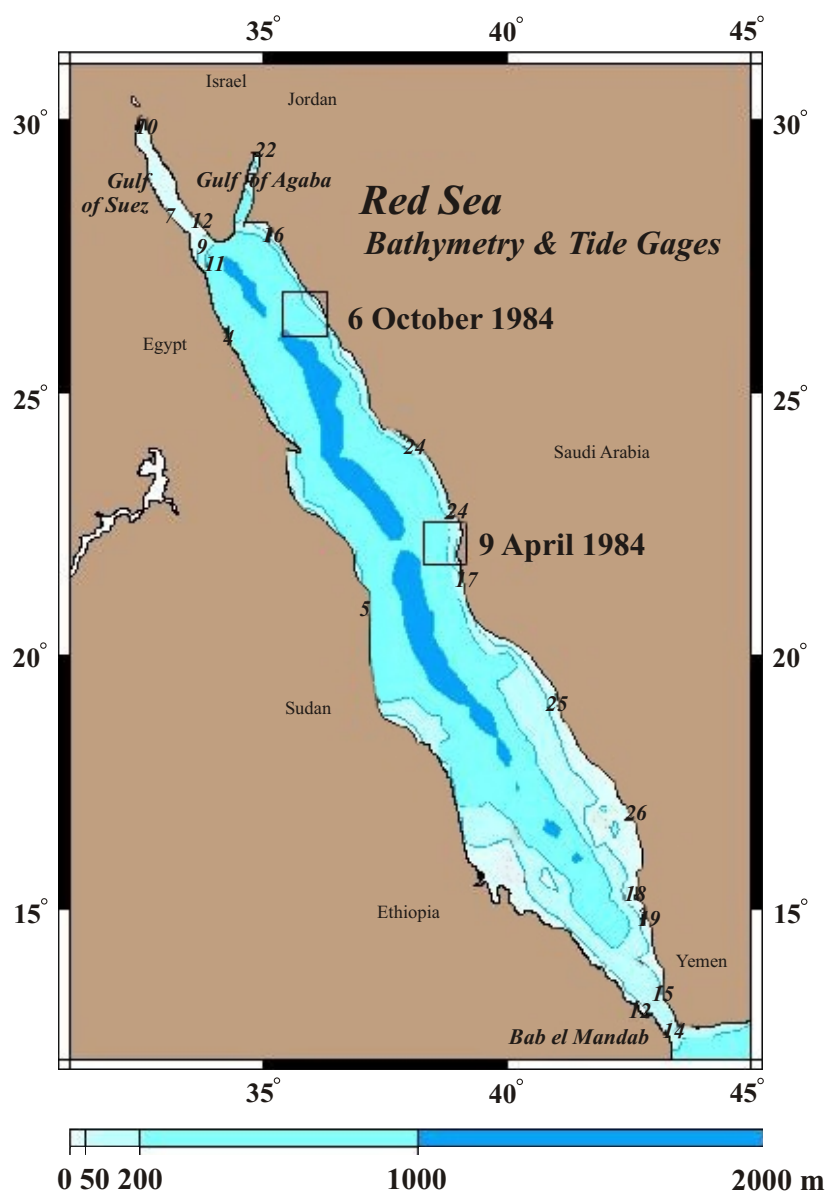

Fig. 1. The bathymetric map of the Red Sea.

correspond to the "deep" shelf according to our classification.

Two regions of the shelf zone of the Red Sea where surface manifestation of internal waves has been fixed in October 1984 (Fig. 3) and April 1984 (Fig. 4) (marked with the black squares in Fig. 1) are of particular interest. Both of these regions appeared to take place at the Eastern shore just in front of two sills crossing the deep part of the Red Sea.

In the centre part of the satellite photo Fig. 3 a train of solitons propagating northeast along the Saudi Arabia shoreline is presented. Each of the waves in the solitons packet is accompanied by a short wave (marked area in the figure) starting in parallel to the shoreline normally to the initial wavecrest.

Much more pronounced configuration of similar internal wave transformation observed in the middle of the Red Sea is illustrated in Fig. 4. An interaction of a solitary wave with the shelf edge results in the generation of secondary relatively short internal waves propagating off the shelf break normally to the incident wave. A consistent appearance of the secondary system of three short internal waves could be followed from panel to panel in Fig. 4. The wavelength esti-

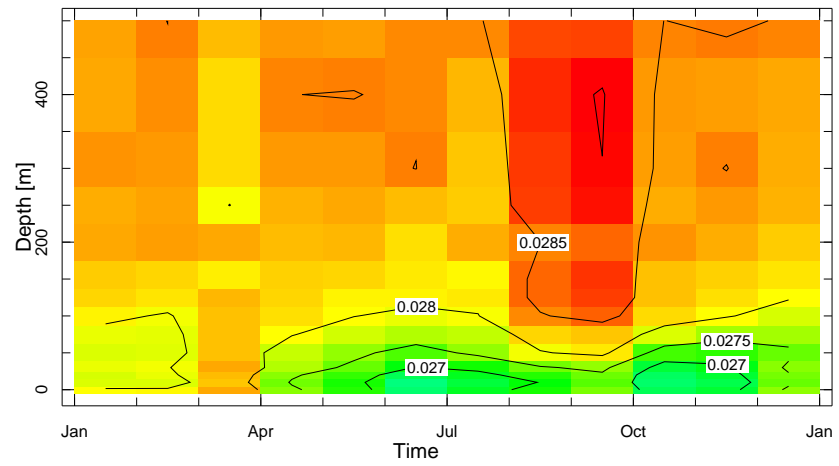

Longitude $35.5 \mathrm{E}$ Latitude $26.5 \mathrm{~N}$

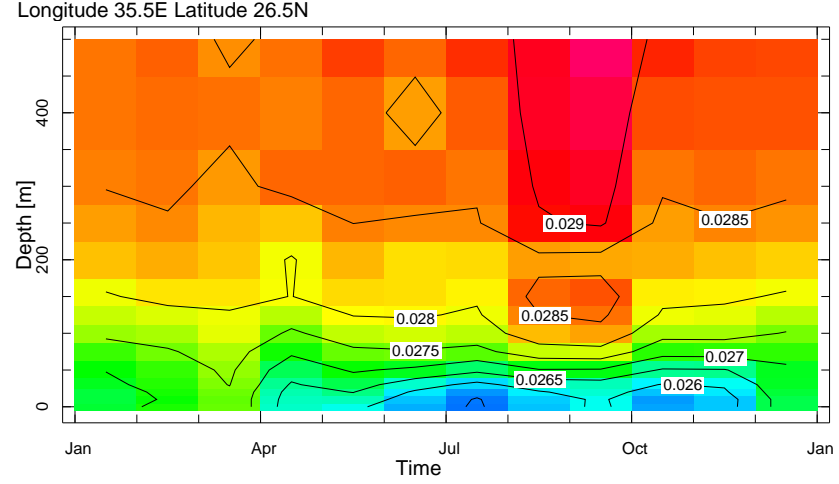

Longitude 37.5E Latitude $23.5 \mathrm{~N}$

Fig. 2. Monthly potential density for the Red Sea (Levitus, 1994).

mated from the satellite views is about $15 \mathrm{~km}$, which equals to the shelf width here. The period of these waves could not be defined because the timing of the photos is not known.

Maillard and Soliman (1986, Figs. 4-6) as well as Quadfasel and Baudner (1993, Fig. 2) performed measurements of the vertical potential temperature, salinity and potential density distribution at the background of the bathymetric crosssection along the Red Sea during different seasons in 1983, 1985 and 1987. According to this data at the latitude $23.5^{\circ} \mathrm{N}$ in October the pycnocline lays at the depth of about $h_{1}=$ $40 \mathrm{~m}$ and internal waves with amplitude $a=100 \mathrm{~m}$ have been observed above the bottom ridge in the middle of the sea.

Unfortunately the exact date of the unique photos made during STS41C NASA mission in April 1984 was not available in the database of the NASA Johnson Space Center. The way of its restoration by means of a comparative analysis of the parameters corresponding to the region of observation estimated with the Giovanni online data system (NASA GES DISC) is described in Appendix A.

To reveal the natural sources of the observed hydrologic phenomena the time series of main meteorological parameters (Fig. A1) as well as the latitude-longitude time-averaged maps of the sea level pressure were reconstructed for the dates of the space flight (Fig. A2). Based on the results of this study, all of the further considerations will be related to 9 April 1984. 


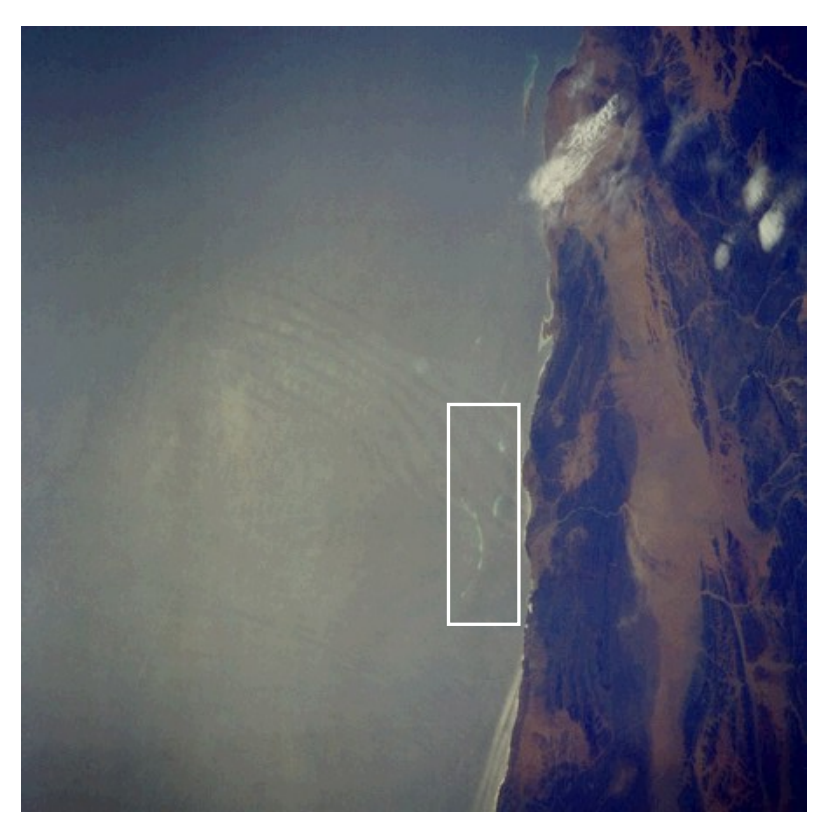

Fig. 3. Satellite image of group of internal solitons in the Red Sea. NASA photo STS41G-36-34 (rotated left) $\left(26.5^{\circ} \mathrm{N}, 36.0^{\circ} \mathrm{E} ; 6\right.$ October 1984; 12:00:47 UTC). Contrast balance was changed.
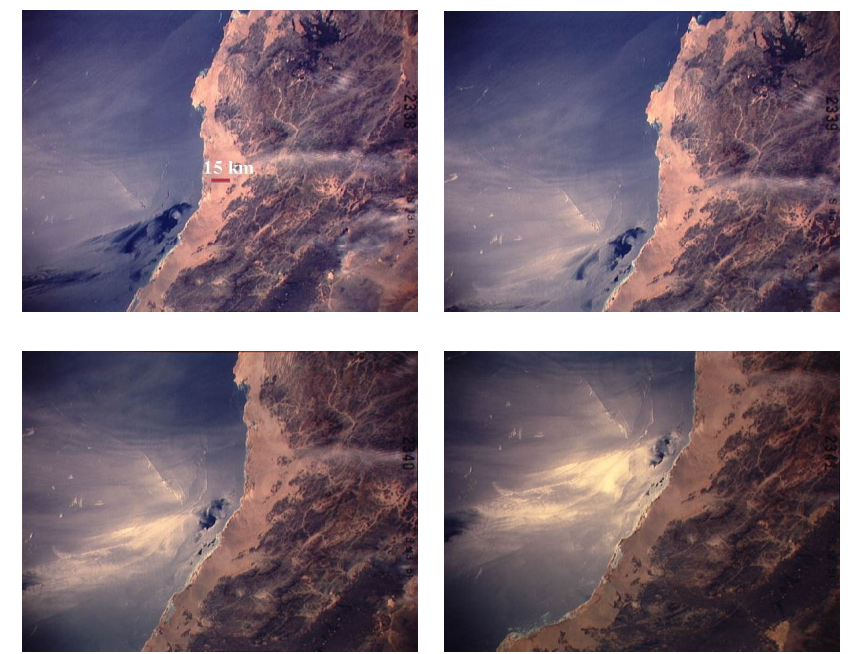

Fig. 4. Satellite images of transformation of internal waves at the shelf edge in the Red Sea. NASA images $\left(23^{\circ} \mathrm{N}, 38.5^{\circ} \mathrm{E}\right.$; April 1984) from left to right and from upper to lower: STS41C-51-2338 $\left(24^{\circ} \mathrm{N}, 38^{\circ} \mathrm{E}\right)$; STS41C-51-2339 (24 $\left.{ }^{\circ} \mathrm{N}, 38^{\circ} \mathrm{E}\right)$; STS41C-51-2340 $\left(23.5^{\circ} \mathrm{N}, 38.5^{\circ} \mathrm{E}\right)$; STS41C-51-2341 $\left(23^{\circ} \mathrm{N}, 38.5^{\circ} \mathrm{E}\right)$.

\section{2 "Shallow" shelf}

Another particular condition of transformation of the solitary waves may be observed in the shelf zone as a result of their generation by tidal internal motions at the bottom irregularities. With further propagation towards the shelf with the bottom slope oriented almost normally to the direction of propagation of the incoming wave.
Internal waves in the Strait of Gibraltar propagating eastward were measured for a long time (Ziegenbein, 1970; Lacombe and Richez, 1982). Further measurements of internal waves in the strait, together with simultaneous visual observations from aircraft and the space shuttle by bathythermograph, radar, infrared scanner collected in October 1982, 1984, and 1985, were presented by La Violette and Arnone (1988).

In the Strait of Gibraltar the strong forcing of the high tide over Camarinal Sill at the western end of the Strait of Gibraltar produces once a day a long solitary wave. While the tidal flow over the sill is westward, an internal lee wave or a hydraulic jump is formed on the westward side of the sill and propagates then to the Alboran Sea. All of the previous works studied mainly internal waves generated by the tidal flow. Our interest relates to the observations of the Ceuta Bay in the northwestern part of the Alboran Sea (see the marked area in Fig. 5).

The Ceuta Bay is the shallowest part of this region where the shelf's width is about $5 \mathrm{~km}$ and is $20 \mathrm{~km}$ long. As it could be estimated from Fig. 6, the depth of the seasonal thermocline in the second decade of October is about $50 \mathrm{~m}$ which is close to the shelf's depth. Thus, the soliton's interaction with the shelf occurs far from the shoreline. And internal waves cannot propagate onto the shelf because of the narrow lower layer of the stratification above its bottom. Such hydrological conditions relate to the case of the "shallow" shelf in our terms.

In Fig. 7 the result of the interaction of groups of solitons, produced during three tidal periods, with the shelf zone is shown. Several structures of internal waves could be distinguished here - just formed semi-circular waves (region I in Fig. 7) as well as groups of plain solitons propagating across the Alboran Sea (region II in Fig. 7).

According to satellite observations, followed by SAR measurements, the fine structure of sea currents caused by the presence of waters with different densities is manifested in radar images as quasiperiodic slick strips of a horizontal scale from tens of metres to several kilometres. The strips are typically oriented along the currents indicating their jet character and intermittence. This surface picture differs from, for example, near-surface flow caused by atmospheric front (Lavrova et al., 2012; Figs. 5 and 6).

The existence of such flows in the case of the "shallow" shelf is in agreement with the experimental results described in Sect. 3.2, where an explanation of the observed phenomenon will be done.

The comparison of the transformed solitons with the structure of the mixed layer field has shown that the soliton packages here followed the horizontal density gradient according to the deepening mixed layer depicted in Fig. 8.

Though there was no opportunity to estimate the corresponding hydrology for the Alboran Sea on 12 October 1984, there is another photo of the similar internal wave field related to April-May 2002 (Fig. 9). At this time the seasonal 


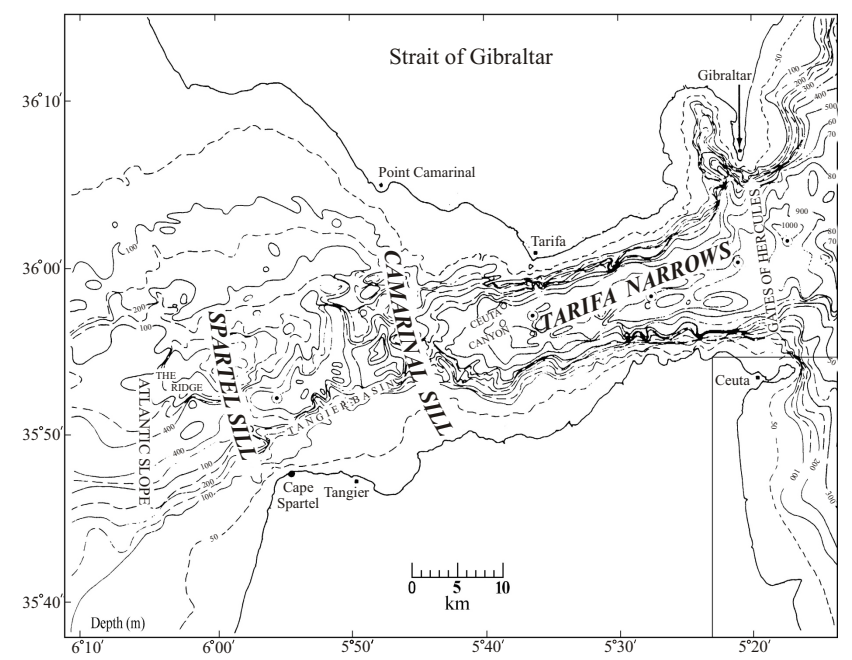

Fig. 5. The bathymetry of the Strait of Gibraltar (Lacombe and Richez, 1982).

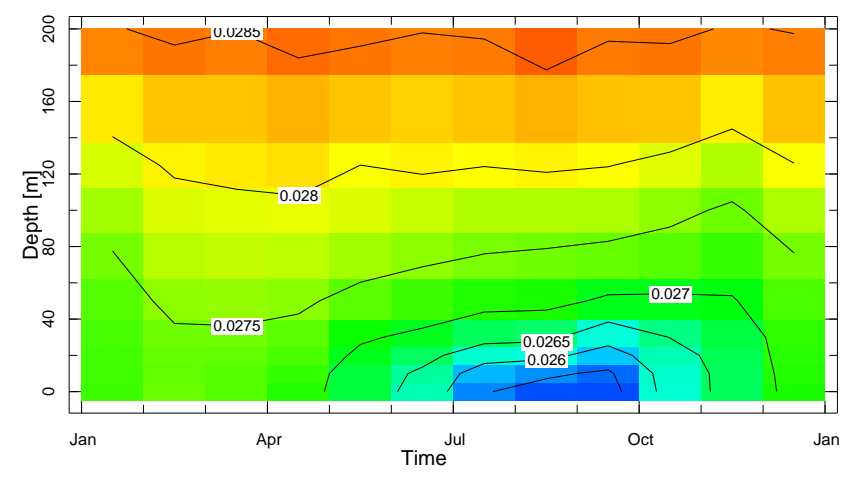

Longitude 4.5W Latitude $35.5 \mathrm{~N}$

Fig. 6. Monthly potential density for the Alboran Sea $\left(35.5^{\circ} \mathrm{N}\right.$, $4.5^{\circ} \mathrm{W}$ ) (Levitus, 1994).

pycnocline has less depth and is not so suppressed just above the shelf bottom as in the first part of October (see Fig. 6). So the induced shear flow at the shelf is not so strong, but it may be seen near the shore of the Ceuta Bay as well (the region of interaction is shown with the white rectangle). Visualization and analysis of the mixed layer thickness based on ocean colour radiometry were performed with the NASA Ocean Biogeochemical Model (NOBM). The date of the shot was defined with the method presented in Appendix A.

It is necessary to mention that in another case of propagation of the tidally generated solitary wave over Camarinal Sill described by La Violette and Arnone (1988), the soliton propagates strictly eastward from the strait and does not turn to the north in the Alboran sea. The shear flow induced at the shelf in the Ceuta Bay and the Gibraltar Bay is much less pronounced, but may be still distinguished by means of remote sensing (see Fig. 9). The observed solitons again follow the horizontal density gradient for the period of observation on 20 June 2001.
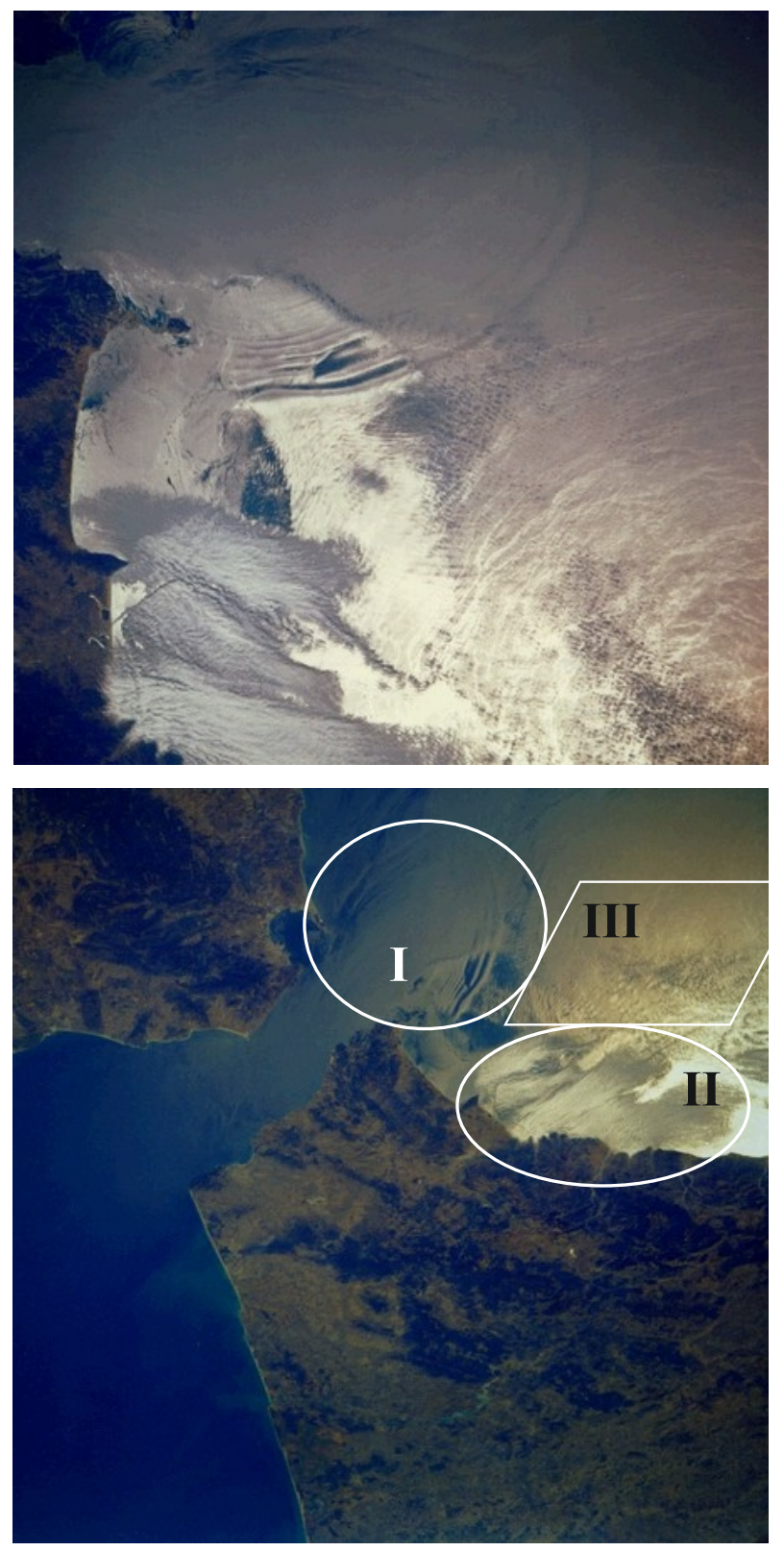

Fig. 7. Surface manifestation of hydrodynamic phenomena: initial internal waves (I), periodic shear flows (II) and internal waves of the previous tidal period (III) in the Alboran Sea $\left(36^{\circ} \mathrm{N}, 5.5^{\circ} \mathrm{W}\right.$; 12 October 1984): NASA photos STS41G-34-98 (12:04:06 UTC) (rotated left) and STS41G-40-51(12:04:09 UTC). Colour balance and brightness were modified to achieve appropriate view of details.

\section{Comparison with experimental measurements}

The hydrological phenomena revealed in Sect. 2 with the satellite photos and SAR images were modelled in the laboratory conditions. 


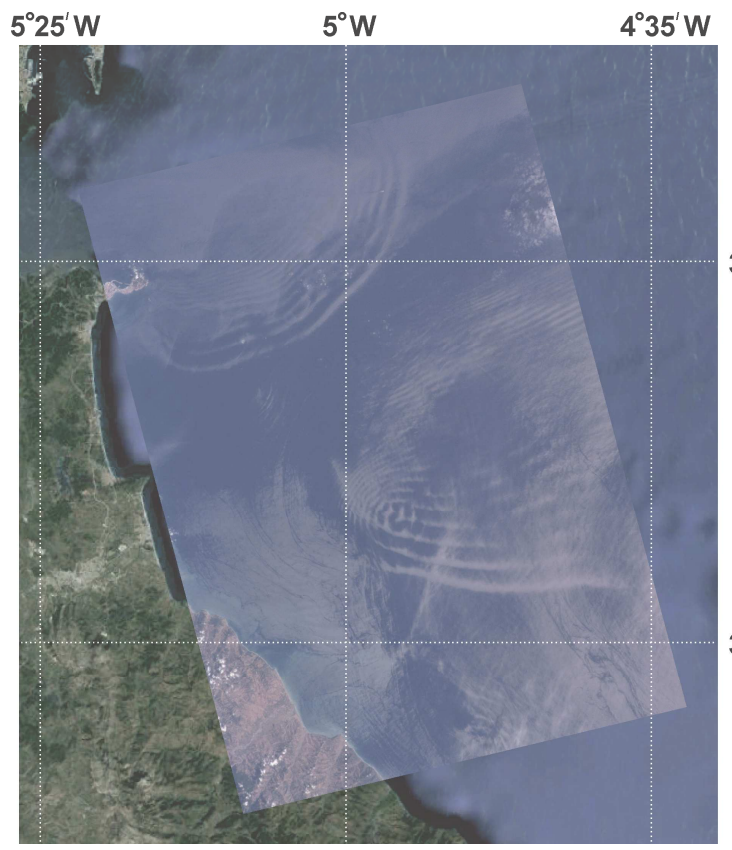

$35^{\circ} 55^{\prime} \mathrm{N}$

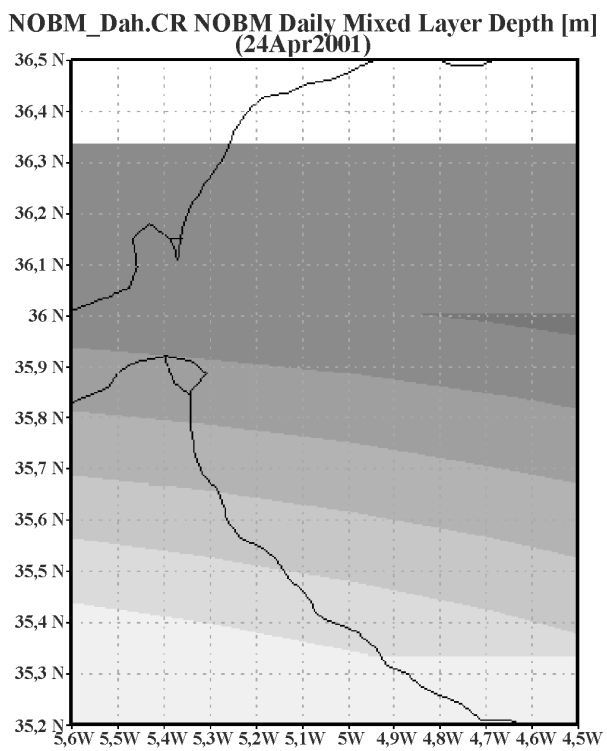

Fig. 8. Free surface manifestation of internal solitons in the Alboran Sea: (NASA photo ISS002-351-23 (adapted to the land relief), mission dates from 20 April to 4 May 2001 (no date for the photo). At the panel below the day-averaged mixed layer depth is shown for 24 April 2001 (corresponding date was defined with the method described in Appendix A).

\subsection{Laboratory facility}

The construction of the tank, the procedure of formation of the stratification profile and the method of flow visualization are described in Grue et al. (1999). The tank with its overall dimensions $L \times B \times H=12.0 \times 0.5 \times 1.0 \mathrm{~m}^{3}$ (Fig. 10) was filled with a two-layer stratified fluid (fresh wa-
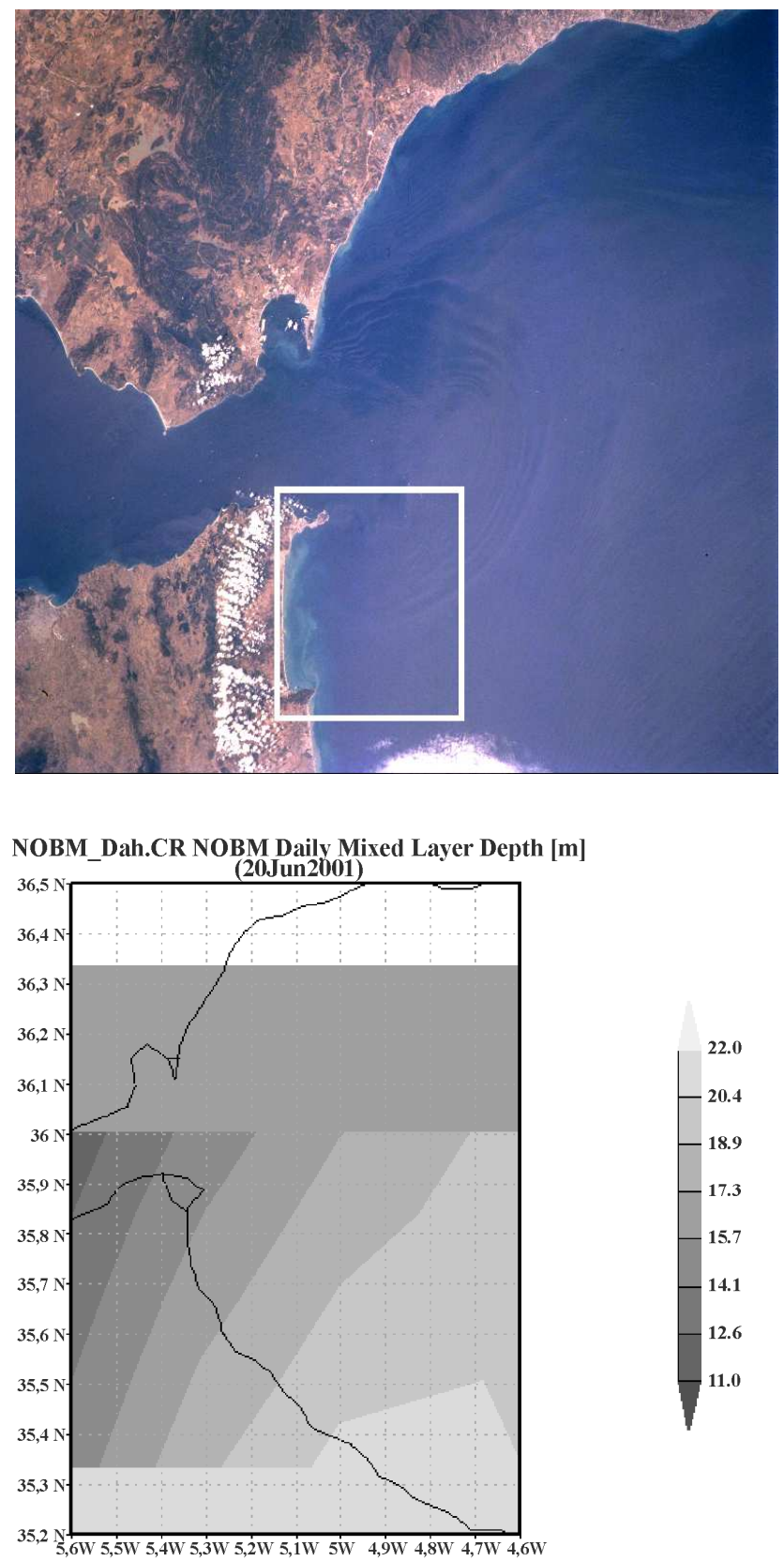

Fig. 9. Free surface manifestation of internal solitons in the Alboran Sea NASA photo ISS002-724-12 (20 June 2001). Colour brightness was modified to achieve appropriate view of details. The mixed layer depth averaged over 20 June 2001 is displayed below.

ter over salt water made by sodium chloride) with the layer's thickness $h_{1}=0.1 \mathrm{~m}, h_{2}=0.615 \mathrm{~m}$ and respective densities $\rho_{1}=0.999 \mathrm{~kg} \mathrm{dm}^{-3}, \rho_{2}=1.022 \pm 0.001 \mathrm{~kg} \mathrm{dm}^{-3}$. Visualizing seeds had neutral buoyancy at the level of the interface between two homogeneous fluids.

Visualization of the flow was performed both in vertical and horizontal directions. Vertical light sheets performed with the laser were positioned at two points along the tank 


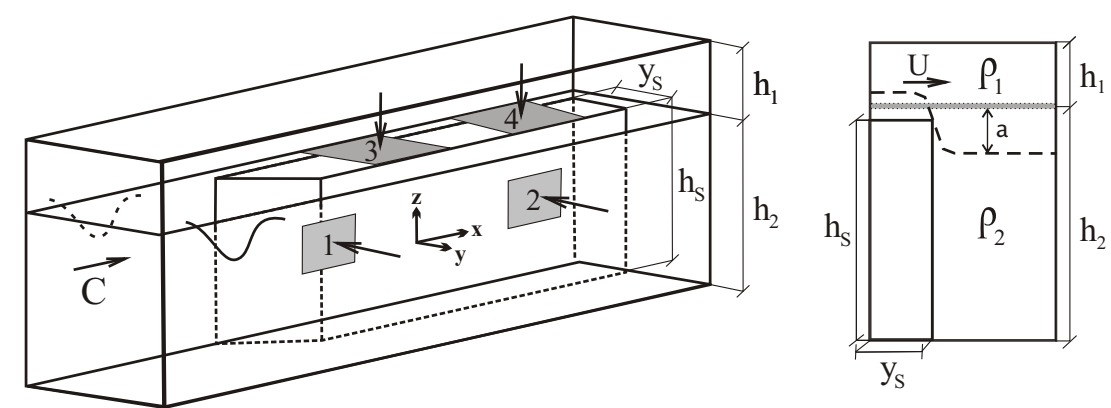

Fig. 10. Sketch of the experimental facility (numbers at the left figure denote positions of video-cameras).

$(x=4.1 \mathrm{~m}$ and $8 \mathrm{~m}$ ). The first lighting was organised close to the wall opposite to the shelf to fix the parameters of the incoming wave. The horizontal light sheet for camera 2 at the tank's length of $6.8 \mathrm{~m}$. Two other light sheets (cameras 2 and 4) have been used for investigation of particles transport at the shelf by the wave passing along the deep part of the tank.

\subsection{Results of laboratory observations}

The incoming wave was in fact a solitary wave of the length $\lambda=0.6 \mathrm{~m}$ and the period $\tau=15 \mathrm{~s}$. It is a typical feature of strongly nonlinear solitons, contrary to $\mathrm{KdV}$ solitons, to keep their length almost non-variable versus considerably increasing wave amplitude (Fig. 4 in Choi and Camassa, 1999, as well as Fig. 7 in Grue et al., 1999).

While the KdV model displays a decrease of the soliton's length twice the strongly nonlinear solitons change their length of about $20 \%$ in a wide range of the same values of amplitude. So the solitary wave length remains almost constant in different experiments (see e.g. Figs. 3 and 6 in Camassa et al., 2006).

The effective length of a strongly nonlinear travelling solitary wave was defined by its volume divided by the amplitude (Koop and Butler, 1981)

$\lambda=\left|\frac{1}{a} \int_{0}^{\infty} y(x) \mathrm{d} x\right|$,

Maderich et al. (2009) suggested the criterion to distinguish moderate and strongly nonlinear solitary wave. A comparison of the limiting soliton amplitudes defined by the weakly nonlinear Gardner and the full Euler equations showed the values of relation between layers thickness $0.6<h_{1} / h_{2}<1$, which corresponds to wave amplitudes greater than $0.2 h_{1}$ or $h_{2} / 3$.

The applicability of the Gardner equation can be analysed by comparison to the limiting solitary waves in the full Euler and the Gardner equations. According to Euler equations solitary waves also exist for amplitudes less than the maximal value $a_{\lim }=\left(h_{1}-h_{2}\right) / 2$ (Choi and Camassa, 1999; Grue et al., 1999).
For $a / h_{2}<0.05$ the experimental data lie a little below both theoretical curves and show good agreement with the theoretical predictions for $0.05<a / h_{2}<0.2$ (comments for Fig. 5 in Choi and Camassa, 1999). This conclusion concerns the comparison of shallow-water experiments by Koop and Butler (1981) with the KdV and the fully nonlinear theories.

Parameters varying during the experiments were the soliton's amplitude $a=0.025 \div 0.107 \mathrm{~m}$ and the thickness of the lower layer $h_{2}=1.025 h_{\mathrm{s}}$ or $1.083 h_{\mathrm{s}}$, where $h_{\mathrm{s}}=0.6 \mathrm{~m}$. Values of experimental parameters are within the range $0.04<$ $a / h_{2}<0.17$, so both approximations are applicable in this case.

In Camassa et al. (2006), a thorough study of validity of Choi-Camassa strongly nonlinear model relatively to the solution of the full Euler equations was considered. Both asymptotic theory and numerical solutions have displayed a very good mutual agreement and correlation with experimental measurements of parameters of internal solitary waves obtained for the present tank configuration by Grue et al. (1999).

The profile of the solitary waves generated in the tank was calculated with the full Euler numerical model (Grue et al., 1999).

For an inviscid and incompressible fluid of density $\rho_{i}$ the velocity components in Cartesian coordinates $\left(u_{\mathrm{i}}, w_{\mathrm{i}}\right)$ and the pressure $p_{i}$, satisfy the continuity equation and the $\mathrm{Eu}-$ ler equations:

$$
\begin{aligned}
u_{i x}+w_{i z} & =0, \\
u_{i t}+u_{i} u_{i x}+w_{i} u_{i z} & =-p_{i x} / \rho_{i}, \\
w_{i t}+u_{i} w_{i x}+w_{i} w_{i z} & =-p_{i z} / \rho_{i}-g,
\end{aligned}
$$

where $g$ is the acceleration due to gravity and subscripts with respect to space and time represent partial differentiation. In a two-fluid system, $i=1(i=2)$ stands for the upper (lower) fluid (see Fig. 10) and $\rho_{1}<\rho_{2}$ is assumed for a stable stratification.

The boundary conditions at the interface are the continuity of normal velocity and pressure:

$$
\begin{aligned}
& \varsigma_{t}+u_{1} \varsigma_{x}=w_{1}, \varsigma_{t}+u_{2} \varsigma_{x}=w_{2}, \\
& p_{1}=p_{2} \text { at } z=(x, t),
\end{aligned}
$$


where $\zeta$ is a displacement of the interface. At the upper and lower rigid surfaces, the kinematic boundary conditions are given by

$w_{1}\left(x, h_{1}, t\right)=0, w_{2}\left(x,-h_{2}, t\right)=0$,

where $h_{i}$ is the undisturbed thickness of the upper (lower) fluid layer.

The results of numerical study of profiles of solitary waves of depression relating to the experimental conditions are presented in Fig. 11. Respective values of velocity $C$ of wave propagation, the effective wavelength $\lambda$ as well as the characteristic of the fluid flow at the shelf for the whole range of amplitudes of the incident solitary wave are presented in Table 1 . The graphs for normalized effective length $\lambda$ and wave speed $C$ versus amplitude of the solitary wave a are shown in Figs. 12 and 13 respectively.

\subsubsection{Fluid motion induced at the shelf model}

Trajectories of visualizing particles were recorded by four cameras installed in front of each of the light sheets. Then the records were processed with the PIV method and the resulting field of the on-shelf velocities induced by the passing solitary wave was reconstructed. The behaviour of the volume of the fluid layer above the shelf was different depending on the pycnocline's depth.

The top view of the horizontal velocity field in the interface layer measured with PIV method corresponding to the "shallow" shelf is presented in Fig. 14.

When the pycnocline was positioned just above the shelf $\left(h_{2}=1.025 h_{\mathrm{s}}\right)$ the wave could not propagate onto the shelf and the wave's motion was observed within the deep part of the tank only. In this case the shelf flow had a pronounced horizontal character with the period of the solitary wave, i.e. an outflow was observed during the first half of the period $\tau / 2$ and an on-flow later.

Additionally the fluid flow at the shelf appeared to be separated into two volumes. One of them, close to the side wall, has the longitudinal velocity component $V$ only. Another part of the fluid at the shelf had both longitudinal $V$ and transverse $U$ velocity components forming oblique shear flow at the shelf bottom. This flow picture is typical for relatively low wave amplitudes $a / h_{1}<0.5$.

This result is in line with the satellite observations presented in Fig. 7. The values of across-shelf velocity obtained in experimental conditions were estimated $U / c_{0}= \pm 0.2$ relatively to its along-shelf component $V / c_{0}=0.25-0.5$. And different parts of the flow pattern in the satellite photo demonstrate relatively different angles of propagation. The observed free surface pattern forms two couples of changing shear flows oriented obliquely to the shoreline at two different approximate angles -45 and $60^{\circ}$. The same effect was observed in experiments when the transverse velocity of the horizontal flow in on-shelf direction was greater than offshelf (see Fig. 15a). So it may be concluded that two periods

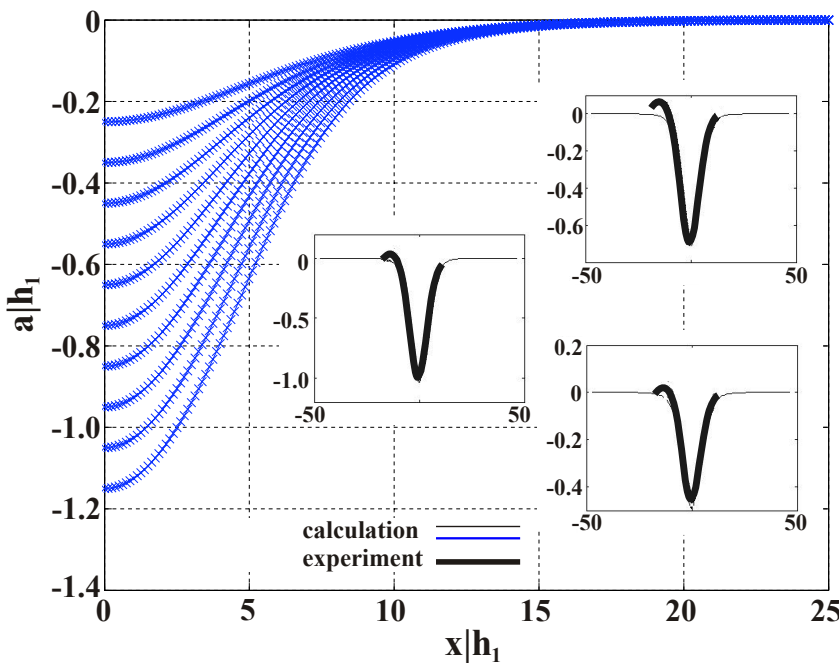

Fig. 11. Profiles of solitary waves of depression calculated via full Euler equations for $\rho_{2} / \rho_{1}=1.022$, $h_{2} / h_{1}=6.15$. Curves correspond to the values of $a / h_{1}=$ $0.25,0.35,0.45,0.55,0.65,0.75,0.85,0.96,1.05,1.15$ (from upper to lower curve respectively). Panels inside illustrate comparison of shapes of induced solitons with the fully nonlinear theory.

Table 1. "Deep" and "shallow" shelf effect versus parameters of solitary waves generated in the tank.

\begin{tabular}{llllll}
\hline$a / h_{1}$ & $\begin{array}{l}\mathrm{C} \\
\left(\mathrm{m} \mathrm{s}^{-1}\right)\end{array}$ & $C / c_{0}$ & $\begin{array}{l}\lambda \\
(\mathrm{m})\end{array}$ & $\begin{array}{l}\text { "deep-shelf" } \\
\text { effect } \\
h_{2} / h_{\mathrm{s}}=1.083\end{array}$ & $\begin{array}{l}\text { "shallow-shelf" } \\
\text { effect } \\
h_{2} / h_{\mathrm{s}}=1.025\end{array}$ \\
\hline 0.25 & 0.150 & 1.09 & 0.700 & - & - \\
0.35 & 0.154 & 1.12 & 0.633 & - & - \\
0.45 & 0.159 & 1.15 & 0.596 & no & no \\
0.55 & 0.162 & 1.18 & 0.575 & no & no \\
0.65 & 0.166 & 1.21 & 0.564 & no & yes \\
0.75 & 0.169 & 1.23 & 0.559 & no & yes \\
0.85 & 0.172 & 1.26 & 0.559 & yes & yes \\
0.95 & 0.175 & 1.28 & 0.563 & yes & yes \\
1.05 & 0.178 & 1.2964 & 0.57 & - & - \\
1.15 & 0.181 & 1.3148 & 0.58 & - & - \\
\hline
\end{tabular}

of wave-induced shear flows at the shallow shelf are fixed at the photo. And width is almost constant for each of four parts of the flow observed above the shelf (area II in Fig. 7).

Based on the experimental data, the amplitude of internal waves propagated in the Alboran Sea is rather high and could be estimated as $a>0.5 h_{1}=25 \mathrm{~m}$.

In case the pycnocline was above the shelf at the distance $h_{2}=1.083 h_{\mathrm{s}}$ so that the lower layer $h_{2}-h_{\mathrm{s}}$ was thick enough for the solitary wave propagation above the shelf as well. And the parameters of the two-layer stratification became different above the shelf and in the deep part of the tank.

Choi and Camassa (1999) concluded that generation of the solitary wave of elevation type is possible when 


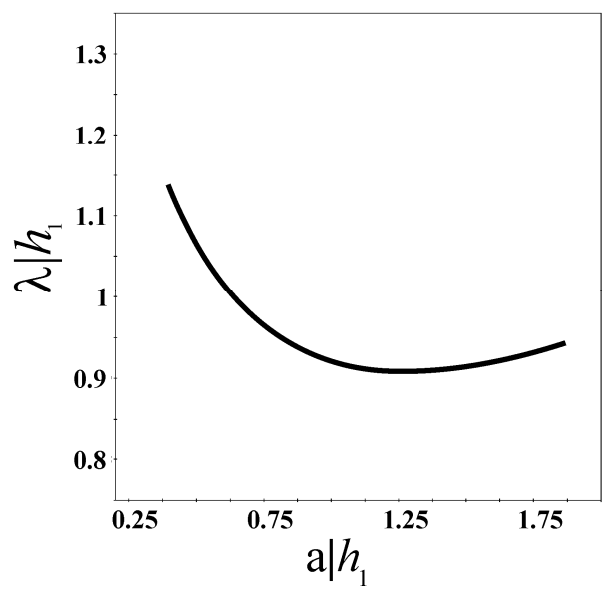

Fig. 12. Effective length $\lambda$ versus amplitude solitary waves of depression calculated via full Euler equations for $\rho_{2} / \rho_{1}=1.022$, $h_{1} / h_{2}=10 / 61.5$.

$\left(h_{1} / h_{2}\right)^{2}>\left(\rho_{2} / \rho_{1}\right)$ as well as for $\left(\rho_{1} / \rho_{2}\right)<\left(h_{1} / h_{2}\right)^{2}<$ $\left(\rho_{2} / \rho_{1}\right)$. And for $\left(h_{1} / h_{2}\right)^{2}<\left(\rho_{1} / \rho_{2}\right)$ the solitary wave is of depression. So strongly nonlinear solitons similar to KdV solitons change their polarity towards a deeper and denser layer of the two-layer fluid.

Time variations of $V$ and $U$ for two values of the fluid thickness above the shelf are presented in Fig. 15. When comparing the upper graphs in the panels it is easy to note the difference between the character of fluid motion produced by the "shallow" and the "deep" shelf. In case of the "shallow" shelf, we could observe an induced horizontal shear flow in the interface layer with its further side-wall reflection within the pycnocline. The transverse velocity component $U$ remains modulo constant but changes its sign immediately after reflection form the wall.

The "deep" shelf produces within the interface layer threedimensional wavy fluid motion normal to the direction of propagation of the solitary wave. The longitudinal velocity component was almost absent after the soliton's passage (central lower graph in Fig. 14). Three periods of short internal waves have been registered during experiment which correlates with the ratio of tank to shelf width $B / y_{\mathrm{s}}=$ $0.50 / 0.17 \approx 3$.

The physical explanation of generation of the secondary short-period internal wave system at the shelf's edge may be found in the frames of the strongly nonlinear internal wave theory.

Particularly in the shelf zone $\left(h_{\mathrm{s}}\right)$ where $\left[h_{1} /\left(h_{2}-h_{\mathrm{s}}\right)\right]^{2}=4>\left(\rho_{2} / \rho_{1}\right)=1.022$ the nonlinear internal wave propagates in the form of elevation of the pycnocline (see Fig. 10). For the deep part $\left(h_{1} / h_{2}\right)^{2}=0.024<\left(\rho_{2} / \rho_{1}\right)=1.022$ and the internal wave causes a decrease of the pycnocline's level.

The vertical deformation of the pycnocline oriented normally to the direction of the internal wave propagation pro-

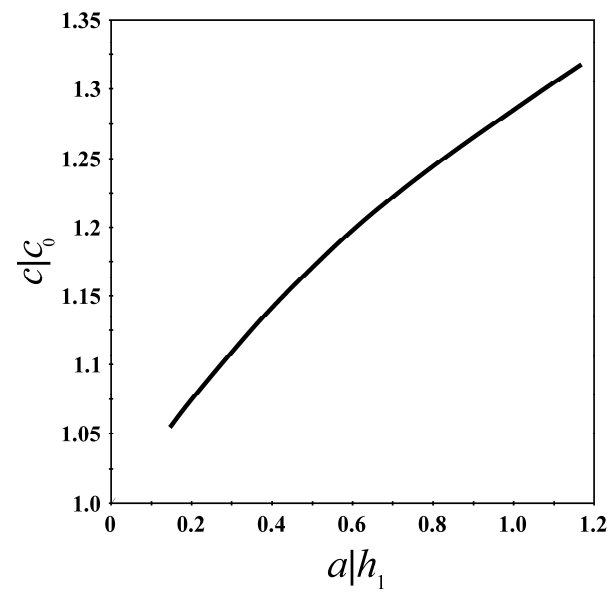

Fig. 13. Wave speed $C$ versus amplitude of solitary waves of depression for $\rho_{2} / \rho_{1}=1.022, h_{1} / h_{2}=10 / 61.5$.

vides the physical conditions for induction of the secondary internal wave system normal to the initial wave. And longitudinal propagation of the solitary wave along the tank transformed to the transverse wave motion with the wavelength of about the shelf's width $\lambda^{*} \approx y_{\mathrm{s}}$ (see upper graphs in Fig. 15).

The results related to the "deep" shelf experimental conditions (see Sect. 2.1) are in a good agreement with the surface manifestation of internal processes shown at the satellite images in Fig. 4.

In case the wave amplitude $a>h_{2}-h_{\mathrm{s}}$ intense fluid mixing was observed at the level of the pycnocline. This highfrequency disturbance was fixed by the measuring system and is illustrated at the upper graph in Fig. 15. After the wave's passage the pycnocline initially representing a sharp density jump had its thickness of about $h_{1} / 2$.

\section{Conclusions}

The main goal of the comparative study of satellite data with laboratory experiments was to model two typical conditions observed in the shelf zone and caused by passing solitons - secondary short internal waves and periodic shear flows induced in the shallow part of the shelf.

Remote observations as well as the experimental study gave evidence to conclude that bottom irregularities normal to the direction of propagation of the solitary waves as plane waves in the presence of the seasonal pycnocline can induce near-bottom shear flows or three-dimensional wave motion with the wave vector normal to that of the incoming wave.

In the "shallow" shelf condition internal waves do not propagate onto the shelf because of the thinness of the layer between the pycnocline and the shelf bottom. So the internal processes are represented by the shear flow within the upper quasi-homogeneous layer only. 

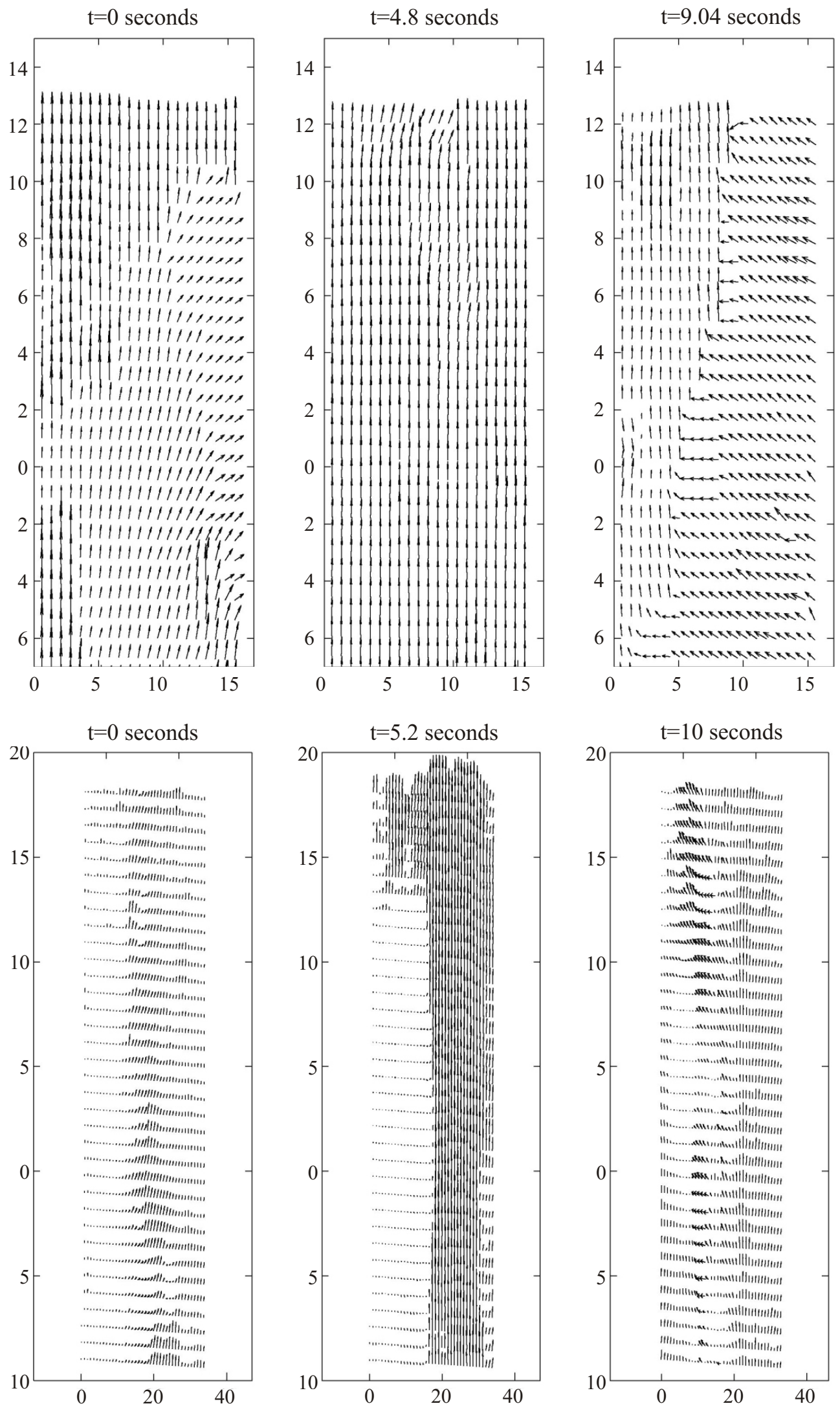

Fig. 14. Top view of horizontal velocity field at the "shallow" (upper) and "deep" (lower) shelf. 

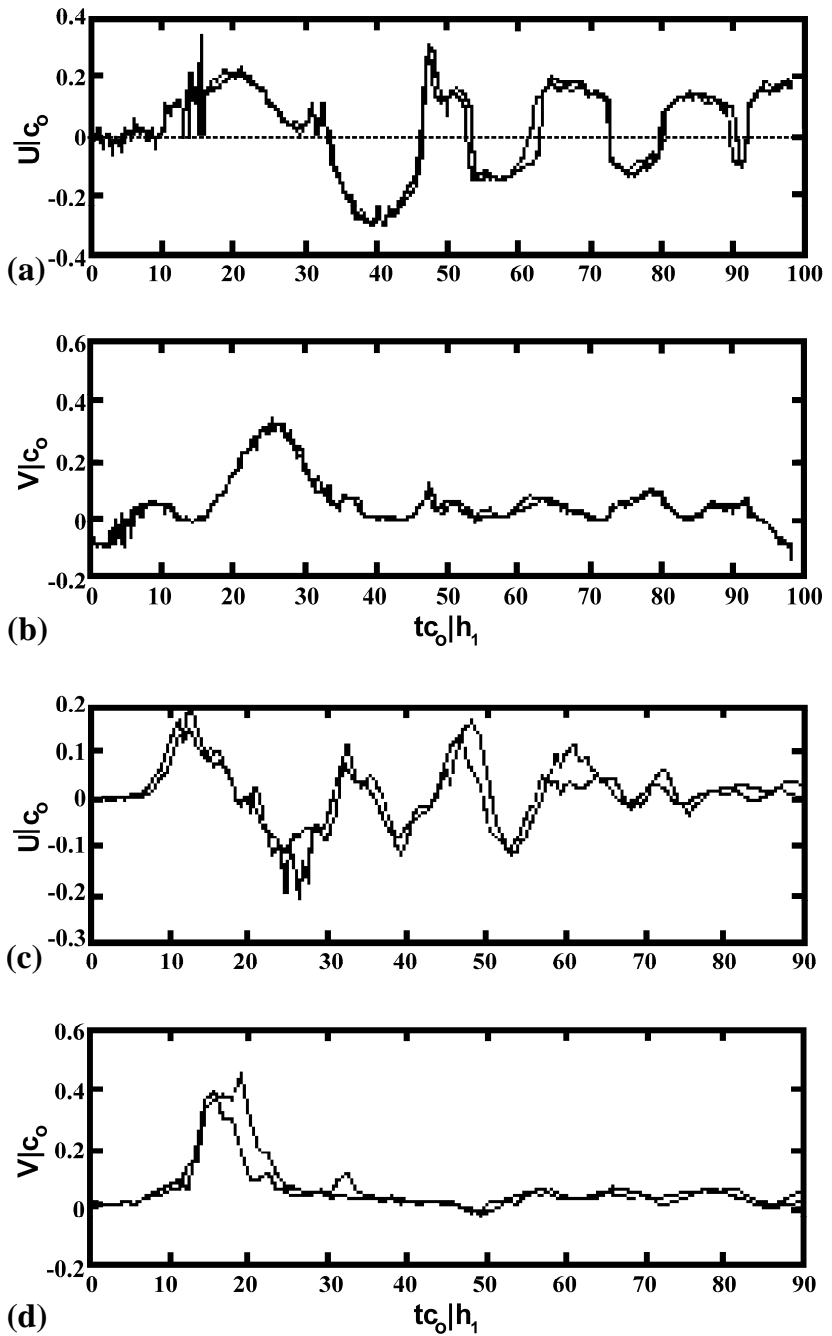

Fig. 15. Time series of transverse $U$ (normal to the shelf) and longitudinal $V$ (along the shelf) velocity components in two close points at the shelf edge (two curves in each panel) (camera 2; $x=6.8 \mathrm{~m}$, $y=0.17 \mathrm{~m}$ ): $\mathbf{a}, \mathbf{b}-$ the "shallow" shelf; $\mathbf{c}, \mathbf{d}-$ the "deep" shelf.

Propagation of the solitary wave along the transverse steplike bottom under the "deep" shelf condition demonstrated the nonlinear mechanism of formation of "runaway" edge internal waves contrary to known "trapped" edge waves.

This type of internal waves could be generated under respective variation of hydrological conditions providing change of the soliton's polarity above the shelf edge along the wave crest and across direction of its propagation. In this case propagation of the incident internal wave of depression is followed by generation of secondary transverse periodic wave system propagating off-shore with the wave-length of about the shelf's width.

The phenomenon observed in the experimental conditions with PIV visualization of the fluid flow confirms the mechanism of mass and energy exchange between the shelf and the deep part of the ocean due to induction of intense motion at the shelf's edge. According to the experimental estimations this happens when the relative value of the amplitude of the incident wave $\bar{a} \bar{J}\left(h_{2}-h_{\mathrm{s}}\right) \geq 1.7$.

Any intermediate dependences between the "shallow" and the "deep" shelf typical conditions could not been obtained in experiments with the applied PIV method because of rather complicated 3-D flow structure. This requires more precise visualizing technique as well as the application of statistical methods of evaluation of measured parameters. And will be the matter of the further study.

Taking into account the finite dimensions of the experimental installation the series of the performed experiments may be considered as a model of propagation of internal waves in the restricted natural conditions, e.g. in channels or straights.

The obtained results may be useful for solution of the problems arising during planning of the field and remote oceanographic investigations including the shelf zone, e.g. for positioning of any equipment, planning of imagery or underwater manipulations. Some particular interest this investigation may be represented by the ecological viewpoint for modelling and prediction of the spreading of pollution in the shelf zone.

\section{Appendix A}

\section{Justification of the absent date of satellite images}

Dealing with the satellite image database the authors met the problem of the lack of dates of some photos. Particularly, there is no systematic date of the photos for the time period related to NASA mission STS41C from 6 to 13 April 1984.

To make any reasonable analysis of peculiarities of the observed hydrological fields it was necessary to distinguish the real date of each shot within the known period of the space flight. This became possible due to performing an additional study of a number of specific fields of the areas of observation. In different cases the role of the flow markers could be played by the parameters of reflection of different frequency bands of the radar beam following, e.g. chlorophyll distribution.

To clarify this item, four different meteorological parameters were calculated within the area of investigation. Time series of the latent heat flux, the sea level pressure and the surface skin temperature yielding hourly 2-D data analysis made with MERRA system installed within Giovanni interface are presented in Fig. A1.

An increase of the latent heat flux and the sea-level pressure presented in Fig. A1 appeared to be the most informative parameters contrary to the periodically varying surface temperature. Though the latter displayed some variation in the day-to-night amplitude, it was relatively weak to fix the possible time and source of the internal waves generation 

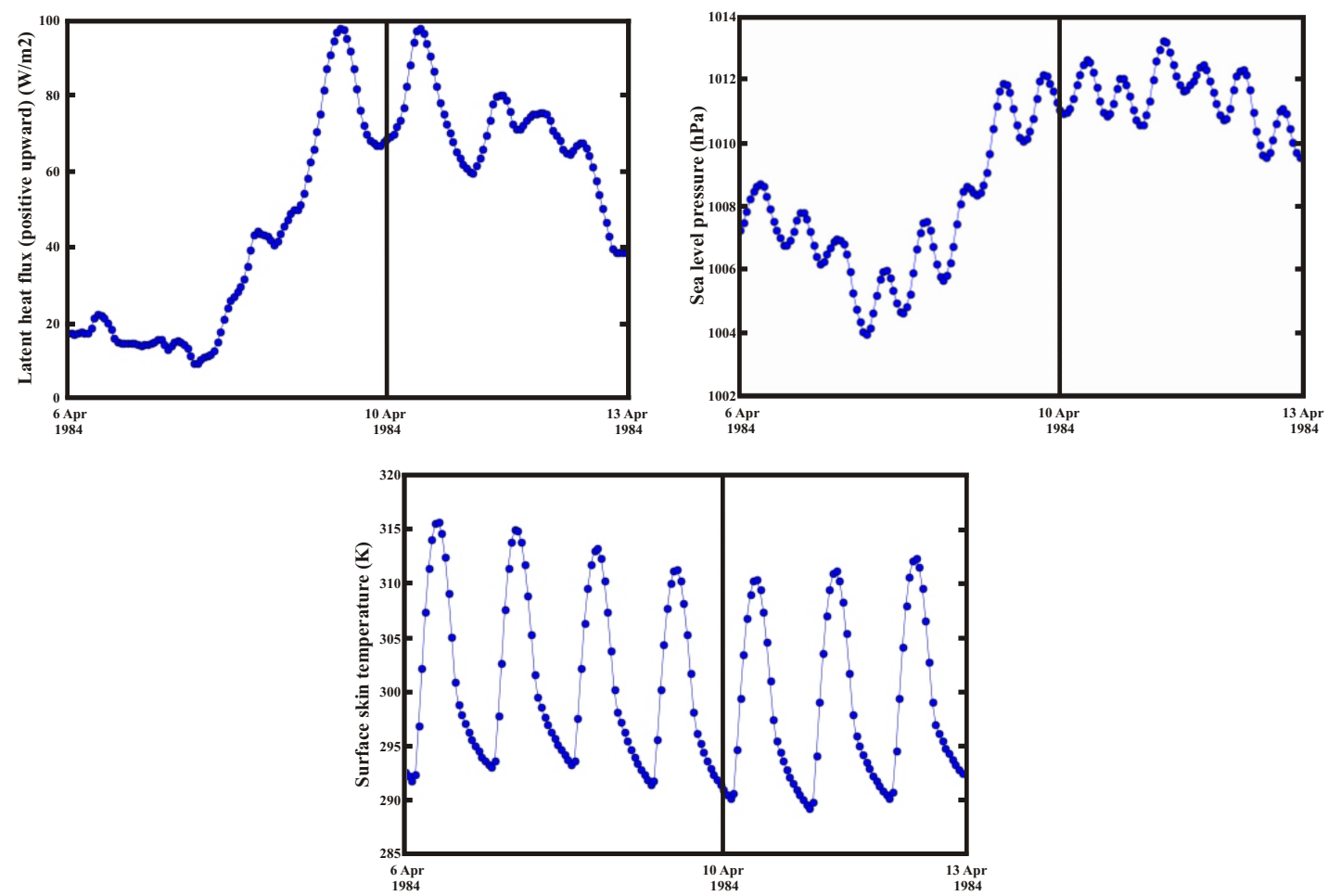

Fig. A1. Time series of latent heat flux, sea level pressure and surface skin temperature for the shelf region of the Red Sea shown in Fig. 4 corresponding to NASA mission STS41C (6-13 April 1984).
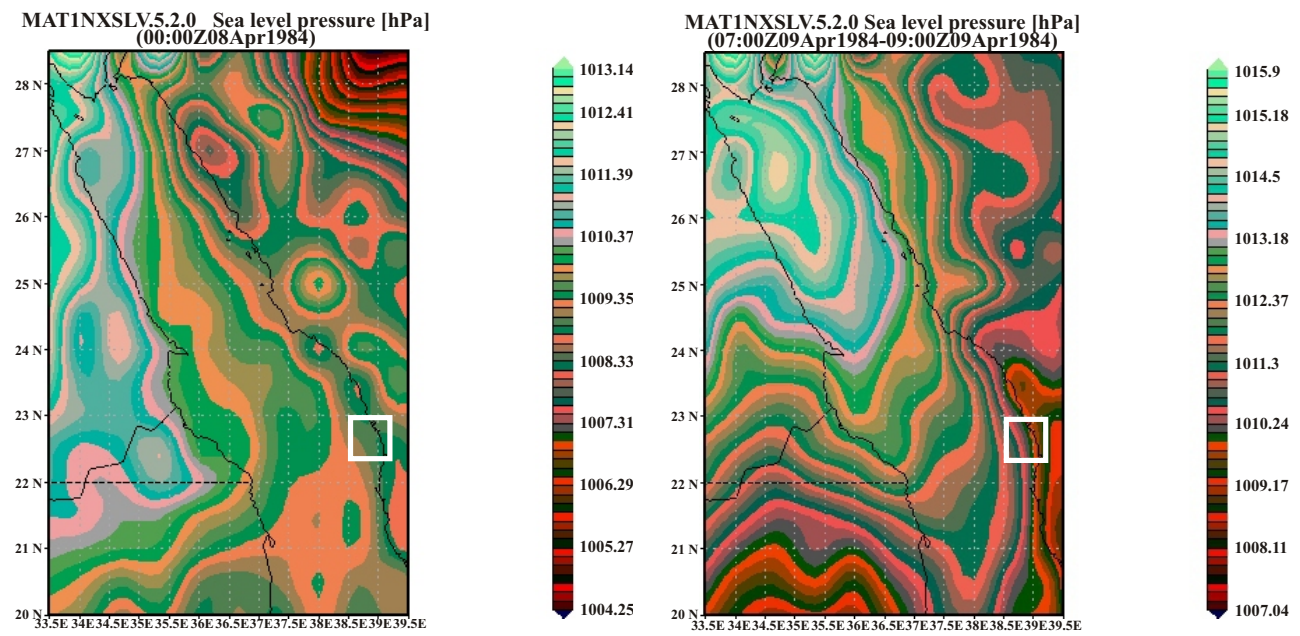

Fig. A2. Sea level pressure related to STS41C NASA mission 0 a.m.-1 p.m. on 9 April 1984 (white square corresponds to Fig. 4).

and was used mainly for more exact date definition. So the growth of the lateral heat flux followed with the increasing sea-level pressure could be considered as the most possible reasons for the appearance of the transverse internal solitary wave in the middle part of the Red Sea.

A restoration of the distribution of the sea level pressure presented in Fig. A2 with 2-h time interval related to 9 April 1984 proved a considerable change in orientation of the pressure gradient field at the free surface during the stud- ied period. Mean orientation of the pressure field has been changing from along-shore to across-shore during day time. An intense motion of water masses driven by the pressure field over the bottom seal in front of the region of the satellite observation (the white square at the figures) could be reasonably considered as the source of the internal soliton generation. Based on this study, the date of performance of NASA photo series STS41C-51-2338/2341 was considered as 9 April 1984. 

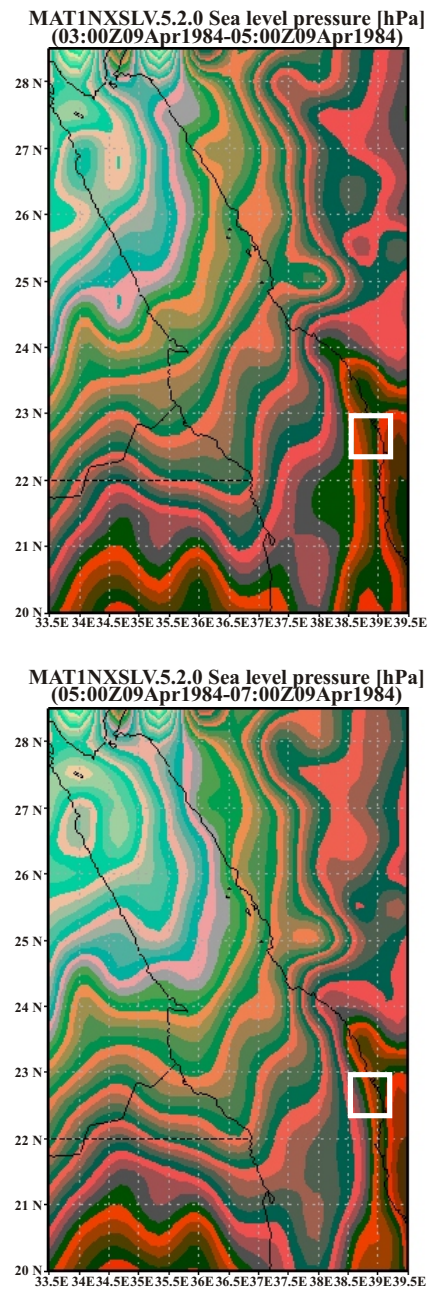
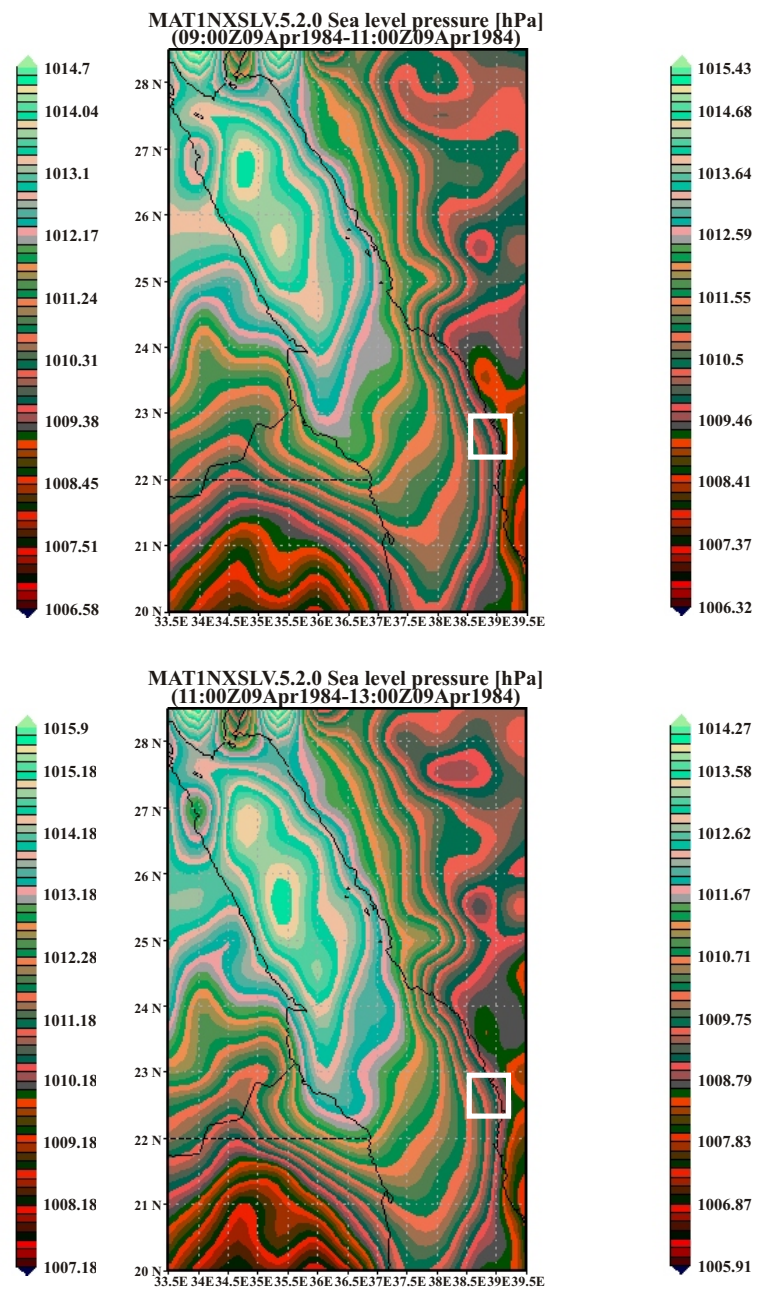

Fig. A2. Continued.

Acknowledgements. Olga Shishkina would like to express her deepest gratitude to the Hydrodynamic Laboratory at the Department of Mathematics of the University of Oslo for the opportunity to perform the experiments.

Original satellite images courtesy of Image Science \& Analysis Laboratory, NASA Johnson Space Center, "The Gateway to Astronaut Photography of Earth". Analyses and visualizations used in this paper were produced with the Giovanni online data system, developed and maintained by the NASA GES DISC.

Edited by: R. Grimshaw

Reviewed by: T. Talipova and one anonymous referee

\section{References}

Armi, L. and Farmer, D. M.: The flow of Atlantic water through the Strait of Gibraltar, Prog. Oceanogr., 21, 1-105, 1988.

Baines, P. G.: Satellite observations of internal waves on the Australian North West Shelf, Aust. J. Mar. Fresh. Res., 32, 457-463, 1981.

Behairy, A. K. A., Sheppard, C. R. C., and El-Sayed, M. K.: A review of the geology of coral reefs in the Red sea, UNEP Regional Seas Reports and Studies, 152, 22-24, 1992.

Boegman, L., Ivey, G. N., and Imberger, J.: The degeneration of internal waves in lakes with sloping topography, Limnol. Oceanogr., 50, 1620-1637, 2005.

Brandt, P., Alpers, W., and Backhaus, J. O.: Study of the generation and propagation of internal waves in the Strait of Gibraltar using a numerical model and radar images from the European ERS-1 satellite, J. Geophys. Res, 101, 14237-14252, 1996.

Buchan, S. J. and Pritchard, W. G.: Experimental observations of edge waves, J. Fluid Mech., 288, 1-35, 1995. 
Camassa, R., Choi, W., Michallet, H., Rusås, P.-O., and Sveen, J. K.: On the realm of validity of strongly nonlinear asymptotic approximations for internal waves, J. Fluid Mech., 549, 1-23, 2006.

Cheng, M.-H., Hsu, J. R.-C., and Chen, C.-Y: Laboratory experiments on waveform inversion of an internal solitary wave over a slope-shelf, Environ. Fluid Mech., 11, 353-384, 2011.

Choi, W. and Camassa, R.: Fully nonlinear internal waves in a two fluid system, J. Fluid Mech., 396, 1-36, 1999.

Constantin, A.: Edge waves along a sloping beach, J. Phys. A-Math. Gen., 34, 9723-9731, 2001.

Da Silva, J. C. B., Ermakov, S. A., Robinson, I. S., Jeans, D. R. G., and Kijashko, S. V.: Role of surface films in ERS SAR signatures of internal waves on the shelf. 1. Short-period internal waves, J. Geophys. Res., 103, 8009-8031, 1998.

Da Silva, J. C. B., New, A. L., and Azevedo, A.: On the role of SAR for observing "local generation" of internal solitary waves off the Iberian Peninsula, Can. J. Remote Sens., 33, 388-403, 2007.

Evans, D. V. and McIver, P.: Edge waves over a shelf: full linear theory, J. Fluid Mech., 142, 79-95, 1984.

Greenspan, H. P.: A note on edge waves in a stratified fluid, Stud. Appl. Math., 49, 381-388, 1970.

Grimshaw, R., Pelinovsky, E., and Talipova, T.: Solitary wave transformation in a medium with sign variable quadratic and cubic nonlinearity, Physica D, 132, 40-62, 1999.

Grimshaw, R., Pelinovsky, E., Talipova, T., and Kurkin, A.: Simulation of the transformation of internal solitary waves on oceanic shelves, J. Phys. Oceanogr., 34, 2774-2791, 2004.

Grue, J., Jensen, A., Rusås, P.-O., and Sveen, J. K.: Properties of large-amplitude internal waves, J. Fluid Mech., 380, 247-278, 1999.

Guo, C., Vlasenko, V., Alpers, W., Stashchuk, N., and Chen, X.: Evidence of short internal waves trailing internal solitary waves in the northern South China Sea from syntetic aperture radar observations, Remote Sens. Environ., 124, 542-550, 2012.

Hajji, H., Bonicel, D., Ramamonjiarisoa, A., Joelson, M., Deveaux, M., Garello, R., and Chapron, B.: Internal waves, topography and ocean fronts and eddies observed with ERS synthetic aperture radar, in: Proc. Oceans'98, 28 September-1 October, 1998, Nice, France, 898-903, 1998.

Helfrich, K. R. and Mellville, W. K.: Long nonlinear internal waves, Annu. Rev. Fluid Mech., 38, 395-425, 2006.

Holloway, P., Pelinovsky, E., Talipova, T., and Barnes, B.: A nonlinear model of internal tide transformation on the Australian North West Shelf, J. Phys. Oceanogr., 27, 871-896, 1997.

Holloway, P., Pelinovsky, E., and Talipova, T.: A generalized Korteweg-de Vries model of internal tide transformation in the coastal zone, J. Geophys. Res., 104, 18333-18350, 1999.

Huthnance, J. M.: Internal tides and waves near the continental shelf edge, Geophys. Astro. Fluid, 48, 81-106, 1989.

Johnson, R. S.: Edge waves: theories past and present, Philos. T. Roy. Soc. A, 365, 2359-2376, 2007

Johnson, R. S.: Water waves near a shoreline in a flow with vorticity: two classical examples, J. Nonlinear Math. Phy., 15, 133-156, 2008.

Kao, T. W., Pan, F.-S., and Renouard, D.: Internal solitons on the pycnocline: generation, propagation, shoaling and breaking over a slope, J. Fluid Mech., 159, 19-53, 1985.

Kinder, T. H.: Net mass transport by internal waves near the Strait of Gibraltar, Geophys. Res. Lett., 11, 987-990, 1984.
Klemas, V., Zheng, Q., and Yan, X.-H.: Ocean internal wave observations using space shuttle and satellite imagery, Geocarto International, 16, 51-55, 2001.

Konyaev, K. V., Sabinin, K. D., and Serebryany, A. N.: Large amplitude internal waves at the Mascarene Ridge in the Indian Ocean, Deep-Sea Res., 42, 2075-2091, 1995.

Koop, C. G. and Butler, G.: An investigation of internal solitary waves in a two-fluid system, J. Fluid Mech., 112, 225-251, 1981.

Kurkin, A. and Pelinovsky, E.: Focusing of edge waves above a sloping beach, Eur. J. Mech. B-Fluid, 21, 561-577, 2002.

Lacombe, H. and Richez, C.: The regime of the Strait of Gibraltar, Hydrodynamics of semi-enclosed seas, Elsevier, 1982.

La Violette, P. E. and Arnone, R. A.: A tide-generated internal wave form in the western approaches to the Strait of Gibraltar, J. Geophys. Res., 93, 15653-15667, 1988.

Lavrova, O., Serebryany, A., Bocharova, T., and Mityagina, M.: Remote sensing of the ocean, sea ice, coastal waters, and large water regions, in: Proc. SPIE 8532, 85320L, doi:10.1117/12.970482, 2012.

LeBlond, P. and Mysak, L.: Waves in the Ocean, Elsevier Oceanogr. Ser., No. $20,1978$.

Lee, C.-Y. and Beardsley, R. C.: The generation of long nonlinear internal waves in a weakly stratified shear flow, J. Geophys. Res., 79, 453-462, 1974.

Liu, P. and Yeh, H.: The generation of edge waves by a wave-maker, Phys. Fluids, 8, 2060-2065, 1996.

Longo, A. M., Manzo, M., and Pierini, S.: A model for the generation of nonlinear internal tides in the Strait of Gibraltar, Oceanol. Acta, 15, 233-243, 1992.

Maderich, V., Talipova, T., Grimshaw, R., Pelinovsky, E., Choi, B. H., Brovchenko, I., Terletska, K., and Kim, D. C.: The transformation of an interfacial solitary wave of elevation at a bottom step, Nonlin. Processes Geophys., 16, 33-42, doi:10.5194/npg16-33-2009, 2009.

Maderich, V., Talipova, T., Grimshaw, R., Pelinovsky, E., Choi, B. H., Brovchenko, I., and Terletska, K.: Interaction of a large amplitude interfacial solitary wave of dispersion with a bottom step, Phys. Fluids, 22, 076602, doi:10.1063/1.3455984, 2010.

Maillard, C. and Soliman, G.: Hydrography of the Red Sea and exchanges with the Indian Ocean in summer, Oceanol. Acta, 9, 249-269, 1986.

Michallet, H. and Ivey, G. H.: Experiments on mixing due to internal solitary waves breaking on uniform slopes, J. Geophys. Res. 104, 13467-13477, 1999.

Miropol'sky, Yu. Z.: Dynamics of internal gravity waves in the ocean, translated and edited by: Shishkina, O. D., Atmospheric and oceanographic sciences library, 24, Kluwer Academic Publishers, Dordrecht, 2001.

Morozov, E. G.: Global semidiurnal internal wave field, Deep-Sea Res., 42, 135-148, 1995.

Morozov, E. G., Trulsen, K., Velarde, M. G., and Vlasenko, V. I.: Internal tides in the Strait of Gibraltar, J. Phys. Oceanogr., 32, 3193-3206, 2002.

Morozov, E. G., Nechvolodov, L. V., and Sabinin, K. D.: Beam propagation of tidal internal waves over a submarine slope of the Mascarene Ridge, Oceanology, 49, 745-752, 2009.

New, A. L. and Da Silva, J. C. B.: Remote-sensing evidence for the local generation of internal soliton packets in the central Bay of Biscay, Deep-Sea Res. Pt. I, 49, 915-934, 2002. 
Osborne, A. R. and Burch, T. L.: Internal solitons in the Andaman Sea, Science, 208, 451-460, 1980.

Ostrovsky, L. A. and Grue, J.: Evolution equations for strongly nonlinear internal waves, Phys. Fluids, 15, 2934-2948, 2003.

Ostrovsky, L. A. and Stepanyants, Y. A.: Do internal solitons exist in the ocean?, Rev. Geophys., 27, 293-310, 1989.

Pierini, S.: A model for the Alboran Sea internal solitary waves, J. Phys. Oceanogr., 19, 755-772, 1989.

Quadfasel, D. and Baudner, H.: Gyre-scale circulation cells in the Red Sea, Oceanol. Acta, 16, 221-229, 1993.

Rodenas, J. A. and Garello, R.: A new automatic internal wave detection and characterisation method for SAR images, in: Proc. Oceans'98, 2, 613-618, doi:10.1109/OCEANS.1998.724312, 1998.

Sabinin, K. D., Serebryanyi, A. N., and Nazarov, A. A.: Intensive internal waves in the World Ocean, Oceanology+, 44, 753-758, 2004.

Segur, H. and Hammack, J. L.: Soliton models of long internal waves, J. Fluid Mech., 118, 285-304, 1982.

Serebryanyi, A. N.: Observation of internal waves reflected from the continental slope of Kamchatka, Dokl. Earth Sci., 374, 11771179, 2000.

Shishkina, O., Litvin, A., Vladimirova, E., Ivanov, D., and Ivanov, V.: Experimental study of periodic linear internal waves transform at the shelf edge, Geophys. Res. Abstr., 12, EGU20106834, 2010a.

Shishkina, O., Kazakov, V., and Bogatov, N.: Laboratory study of edge internal waves over plane and inclined shelf bottom, Geophys. Res. Abstr., 12, EGU2010-6905, 2010b.

Small, J.: A nonlinear model of the shoaling and refraction of interfacial solitary waves in the ocean. Part II: Oblique refraction across a continental slope and propagation over a seamount, J. Phys. Oceanogr., 31, 3184-3199, 2001.

Small, J.: Refraction and Shoaling of Nonlinear Internal Waves at the Malin Shelf Break, J. Phys. Oceanogr., 31, 2657-2674, 2003.

Small, J., Hallock, Z., Pavey, G., and Scott, J.: Observations of large amplitude internal waves at the Malin Shelf edge during SESAME 1995, Cont. Shelf Res., 19, 1389-1436, 1999.

Sou, I. M. and Yeh, H.: Laboratory study of the cross-shore flow structure in the surf and swash zones, J. Geophys. Res., 116, C03002, doi:10.1029/2010JC006700, 2011.
Speich, S., Madec, G., and Crépon, M.: A strait outflow circulation process study: the case of the Alboran Sea, J. Phys. Oceanogr., 26, 320-340, 1996.

Sveen, J. K., Guo, Y., Davies, P. A., and Grue, J.: On the breaking of internal solitary waves at a ridge, J. Fluid Mech., 469, 161-188, 2002.

Szekielda, K. H.: Hyperspectral observations of internal waves, International Journal of Geology, Earth and Environmental Sciences, 2, 79-82, 2012.

Velegrakis, A. F., Oikonomou, E., Theocharis, A., Collins, M. B., Kontoyiannis, H., Papadopoulos, V., Voulgaris, G., Wells, T., and Balopoulos, E.: Internal waves revealed by Synthetic Aperture Radar (SAR) imagery in the vicinity of the eastern Cretan Arc Straits (Eastern Mediterranean), Prog. Oceanogr., 44, 553-572, 1999.

Vlasenko, V. and Alpers, W.: Generation of secondary internal waves by the interaction of an internal solitary wave with an underwater bank, J. Geophys. Res., 110, C02019, doi:10.1029/2004JC002467, 2005.

Vlasenko, V., Stashchuk, N., and Hutter, K.: Baroclinic tides: theoretical modeling and observational evidence, Cambridge University Press, Cambridge, UK, 2005.

Whitham, G. B.: Nonlinear effects in edge waves, J. Fluid. Mech., 74, 353-368, 1976.

Yeh, H. H.: Experimental study of standing edge waves, J. Fluid Mech., 168, 291-304, 1986.

Zhao, Z., Klemas, V., Zheng, Q., and Yan, X.-H.: Satellite observation of internal solitary waves converting polarity, Geophys. Res. Lett., 30, 1988, doi:10.1029/2003GL018286, 2003.

Zheng, Q., Klemas, V., Yan, X.-H., and Pan, J.: Nonlinear evolution of ocean internal solitons propagating along an inhomogeneous thermocline, J. Geophys. Res., 106, 14083-14094, 2001.

Zheng, Q., Yuan, Y., Klemas, V., and Yan, X.-H.: Theoretical expression for an ocean internal soliton SAR image and determination of the soliton characteristic half width, J. Geophys. Res., 106, 31415-31423, 2002.

Ziegenbein, J.: Spatial observations of short internal waves in the Strait of Gibraltar, Deep-Sea Res., 17, 867-875, 1970. 